\title{
Research
}

\section{Transfer of Knowledge on Agroforestry Management Practices: the Structure of Farmer Advice Networks}

\author{
Marney E. Isaac $^{1}$, Bonnie H. Erickson ${ }^{1}$, S. James Quashie-Sam ${ }^{2}$, and Vic R. Timmer ${ }^{1}$
}

\begin{abstract}
Access to knowledge on farm management practices is essential for the maintenance of productive agroforestry systems. Farmers who lack the means to acquire farming knowledge from formal sources often rely on information within their informal social networks. However, little research has explored the explicit structure of farmer communication patterns. We examined advice network structures by using farmer attributes, i.e., kin relationships, community involvement, and imitation, to characterize structural positions and investigated the consequences of such structure on farming practices in cocoa agroforestry systems in Ghana, West Africa. Furthermore, we used a multicommunity approach; we constructed networks for four communities to increase replication and enhance the generality of our conclusions. A high density of advice ties occurred among a small group of farmers, indicating a coreperiphery structure. Settler farmers composed $73 \%$ of core position members, suggesting that social proximity did not control the formation of informal advice structures. Because core farmers were highly participative in community activities, the promotion of community involvement may facilitate the movement of knowledge and social exchange to strengthen informal networks. Farmers in both core and peripheral structural positions indicated that they observed fellow farmers and subsequently adopted their practices. Of highly sought farmers, $84 \%$ used external information, predominately from government institutions, thus functioning as bridging links between formal and informal networks. Both external and farmer-derived sources of knowledge of agroforestry practices were transferred through informal advice networks, providing available information throughout the farming community, as well as a foundation for community-based adaptive management.
\end{abstract}

Key Words: agroforestry; farm management; Ghana; social network analysis; Theobroma cacao

\section{INTRODUCTION}

The management of complex agroforestry systems is largely dependent on the optimization of both ecological and social processes. Specifically, for cocoa (Theobroma cacao L.) agroforestry in Ghana under conditions of low soil fertility and constraints to fertilizer access, farmers frequently develop techniques to promote soil and crop nutrition, as well as maintain shade for healthy plants (Amanor 1994, Boni et al. 2004). Upper canopy trees are retained or planted to regulate light and they consequently increase farm diversity and enhance biomass inputs, improving soil fertility and plant nutrition (Beer et al. 1997, Hartemink 2005, Isaac et al. 2007). Particularly, intricate systems of smallscale production that incorporate trees and integrate understory crops with the cocoa stratum have advanced farm health and production. Often, these techniques of farmer-based system management are conveyed through means such as planting schemes, species selection, and levels of biodiversity (Beer et al. 1997). However, access to knowledge on such farm management practices is essential for adaptive management and the maintenance of productive agroforestry systems.

Although there are formal sources of information on pertinent management practices, e.g., institutionalbased knowledge, previous research has shown that little of this information reaches the desired recipients, and selected target farmers are often not representative of the whole farming community (Boahene et al. 1999). It is assumed that to substitute for or balance this lack of information, other types of informal sources of information are created and 
exist within farming communities (Mortimore and Adams 2001, Campbell 2004); farmers who cannot access information from external sources can presumably draw on knowledge within their social networks (Boahene et al. 1999, Lyon 2003, Romani 2003) and transfer agricultural information via social interactions (Conley and Udry 2001). Information is embedded in these social networks and may only be apparent in the context of relationships and interactions (Granovetter 1973). Thus, the socially based process of learning farming and management practices may rely heavily on social relationships in the larger farming community and informal network structures (Foster and Rosenzweig 1995, Conley and Udry 2001, Lyon 2003, Romani 2003, Davidson-Hunt 2006, Kiptot et al. 2006).

Social network analysis, which is a method that is most often used to elicit, visualize, and analyze social relations and social networks, is a suitable tool with which to examine such properties of farmer knowledge transfer. Network theory describes information creation (Coleman 1990, Lin 2001) and subsequent transfer via personal networks and has a history of linking social ties with access to knowledge and information (Granovetter 1973, Burt 1992, Davidson-Hunt 2006). Previous work on social networks, particularly communication patterns in relation to natural resource management, has been examined (Crona and Bodin 2006) and suggests a need for the investigation of the effects of network structure on resource management (Bodin et al. 2006). Here, we respond to the current discourse on social networks and adaptive management by examining a particular network structure, providing explanations for emerging social patterns (Feld 1981), and proposing consequences of this structure on resource management, particularly agroforestry practices.

The use of diverse farming knowledge is necessary for the maintenance of complex agroforestry systems. Thus, the determination of how techniques advance in agroforestry, specifically via farmer communication and learning networks, is critical to understand barriers for farmer access to information (Mortimore and Adams 2001, O'Neal Campbell 2004, Kiptot et al. 2006). Assuming that informal sources of information are embedded within farming communities and are available to farmers through social interactions, the analysis of social structure is a rational research approach by which to uncover communication patterns. The identification of key actors in the development and transfer of agroforestry practices provides insight into information dissemination and may be a path to productive land use and adaptive management.

Communication patterns may evolve into multiple forms of social organization; for instance, we presumed that the structure of advice seeking was dependent on various mechanisms such as kin ties, friendship, and good farming practices in the shadecocoa agroforestry system that we examined. In general, however, the purposeful selection of individuals that have a particular attribute frequently evolves into a core-periphery structure (Barsky 1999, Borgetti and Everett 1999). Coreperiphery structures are those in which a small group of individuals has a high number or density of ties, for instance, advice-seeking connections. This particular structure arises from a two-class partitioning of individuals: one class for highly sought farmers and the other class for minimally sought farmers. In this type of structure, individuals in core positions generally exhibit a high density of cohesive ties, whereas those in the peripheral positions are minimally connected to the core and to each other (Borgetti and Everett 1999). It is important to remember that this structure pertains to core and peripheral relationships, and not to spatial locations.

We focused on the structural arrangement of informal communication networks by examining relational information on advice seeking within four farming communities that practice cocoa agroforestry in Ghana, West Africa. We had four research objectives. First, we determined the structure of informal farmer advice networks within these farming communities by proposing an appropriate structural model. We hypothesized that a core-periphery model was most appropriate to describe agroforestry advice-seeking networks. Second, we used farmer attributes to characterize the configuration of the structure. Core or peripheral group membership was predicted using regional group distinctions and action-oriented categories, particularly involvement in farming-based activities (Boahene et al. 1999, Haggith et al. 2003) and imitation of fellow farmers (Rogers 1995, Axelrod 1997). Third, we investigated the practical consequences of a core-periphery structure on the introduction and transfer of farming information, as well as the formation and use of social capital within a community. Fourth, we determined the variability and consistency among the four distinct advice 
networks of the four communities. Specifically, do informal advice networks within these farming communities have comparable structures, and can some general statements be made about farming advice networks? By focusing on one type of relationship in multiple communities, we sought to increase the rigor and accuracy of the analysis and to test whether the emerging communication patterns were community specific or whether structural characteristics were generalized.

\section{METHODS}

\section{Study design and data collection}

The study was conducted in Ghana, West Africa, in the moist, semi-deciduous, tropical cocoa-growing district of Sefwi Wiawso ( $06^{\circ} 12^{\prime}$ N and $02^{\circ} 29^{\prime} \mathrm{W}$ ), located in the Western Region. This region had an annual precipitation of approximately $1400 \mathrm{~mm}$ and an average temperature of $26^{\circ} \mathrm{C}$ in 2001 (Boni et al. 2004). The population of Sefwi Wiawso District is 149,000 spread among 60 villages (Ghana Statistical Service 2000).

Interviews were conducted in four farming communities. These separate communities were similar in size, population, location in terms of distance from markets and towns, and access to land, but had no apparent crossover in social relations. We assumed that comparable external forces such as political and economic pressures were imposed on the four communities. One adult from each household of the farming population of each village was interviewed: Network 1, $n=21$; Network 2, $n$ $=23$; Network 3, $n=22$; Network 4, $n=23$. A farmer was defined as a person who currently owns or rents land and has established a cocoa farm. Participant farmers were asked questions about sociodemographics, particularly concerning family associations and advice seeking on farm practices and management (Table 1). In addition, network data were collected using the name-generator technique (Marsden 2005; Table 1).

\section{Analysis}

Farmer responses were coded as binary variables, $\mathrm{i}$. e., the presence or absence of a unidirectional advice tie, and entered into a name-based adjacency matrix (Hanneman and Riddle 2005) to create socio-grams
(Fig. 1). A categorical core-periphery model was used, and the density of ties was determined based on a predefined algorithm by Borgetti and Everett (1999) for simple core-periphery structure. Farmer attributes were operationalized to predict core membership. Farmer attributes were divided into three categories: regional group, level of involvement, and level of imitation.

Regional groups were based on the origin of farmers; this was a binary variable: from the community or from outside the community. The predominant socio-political structure of the study area is semi-autonomous chiefdom (Wilks 1993). The key to social organization within this region is matrilineal descent. By birth, children become a member of their mother's lineage, as well as a citizen of the chiefdom in which this lineage rests (Fortes 1950). Although matrilineal ties are traditionally strongest, marriage and paternal lines are becoming increasingly important because of the influences of external forces such as accumulating private and/or fixed property. This shift has influenced aspects of land tenure, for example, property rights for cocoa farms that favor the paternal/child inheritance system (Fortes 1950, Ward 1958). Because of increasing commodity prices of cocoa and the availability of land in the Western Region of Ghana, many people from outside the region have begun to buy or rent land for cocoa production. Thus, farmers from other areas of Ghana, as well as neighboring countries, are often attracted to this region. In addition, as a result of long-term fluctuating cocoa prices, local community members have both started and abandoned cocoa farming (Boni et al. 2004). Therefore, kinship, money transfer, and social negotiation act as mechanisms for access to land. Thus, both local farmers with a family history from the oldest lineages in the community (kin) and newer settler farmers (migrant farmers from external groups) reside together within these communities. It is assumed that each group will have well-established ties, resulting in higher withingroup than between-group social proximity (McPherson et al. 2001, Romani 2003).

To assess the effects of tie-forming situations on network structure (Feld 1981, Boahene et al. 1999) we used the attribute of farmer involvement in community activities. Involvement was also a binary variable: participation in committees, cooperatives, or communal work, or no participation. Although some farmers that were 
Table 1. Summary of questions used to collect socio-demographic information and specific information on farming activites during initial interviews and second-round interviews performed $1 \mathrm{yr}$ later.

\begin{tabular}{ll}
\hline \hline Type or timing of information & Interview question \\
\hline Socio-demographic information & How long have you farmed in this region? \\
& $\begin{array}{l}\text { Were you born in this community? If not, from which region are you and your } \\
\text { family? }\end{array}$
\end{tabular}

Initial interviews List the names of persons in your community whom you seek for advice on
farm practices.

List the names of persons with whom you discuss farm-related activities.

What type of information do you discuss?

Are you involved in community activities? What type of activities?

Do you observe other farms or farmers?

Have you ever altered your farm practices after observing another farm or farmer?

Second-round interviews

List your sources of information on farming practices and management.

What specific information do you seek from each source?

Do you feel that all sources of information are useful?

Do you conduct on-farm experiments? What type of information do you seek from your experiments?

Do you share your newly acquired or original information with other farmers?

placed in the "no involvement" category may have been involved in community activities, if the farmer did not mention any participation during the interview, it was deemed unimportant to the farmer. We also assessed the imitation of other farmers, which was coded based on discussions of observation. Farmers that acknowledged having observed fellow farmers and subsequently changed their farming practices were assigned to the "imitation" category, whereas those that had not mentioned an interest in observing other farmers were assigned to the "no imitation" category.

A second round of in-depth interviews was conducted individually with each core member $1 \mathrm{yr}$ after the initial interviews. These interviews concentrated on core farmer conduct with regard to developing and seeking information and the specific type of advice sought (Table 1).

We compared the centrality parameters of degree, closeness, and "betweenness" to evaluate the similarity among the four networks (Faust and Skvoretz 2002). Degree is the number of nominations an actor holds. Closeness is the reciprocal of the sum of the geodesic distances between an actor and all other actors, or the reachability of an actor from other actors ("in" closeness) and to other actors ("out" closeness). Betweenness is the level at which an actor is located between other actors. These centrality parameters were averaged for all actors in each network and 
Fig. 1. Socio-grams for community networks (A) 1, (B) 2, (C) 3, and (D) 4. Nodes represent individual farmers and directed arrows represent advice ties.

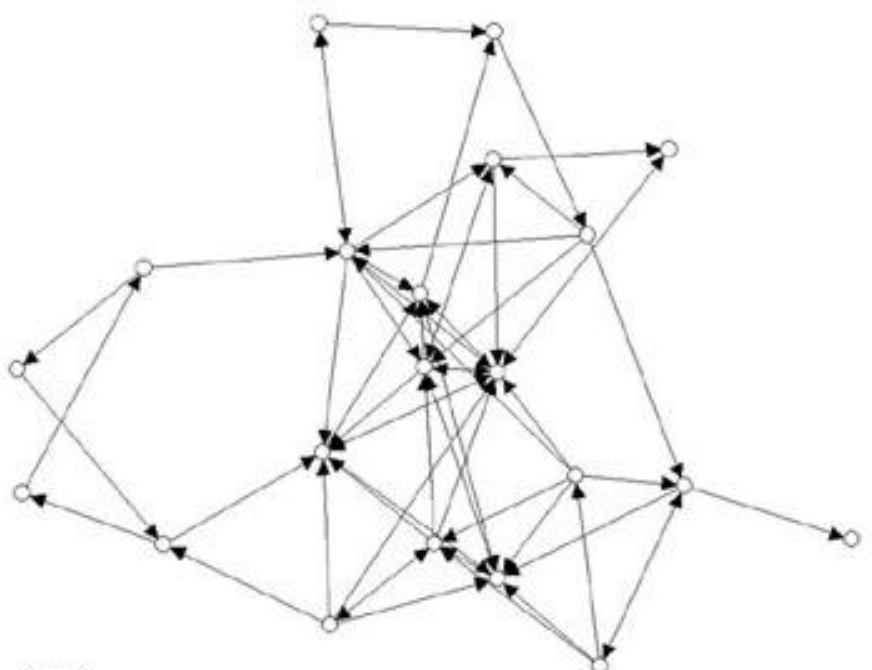

(A)

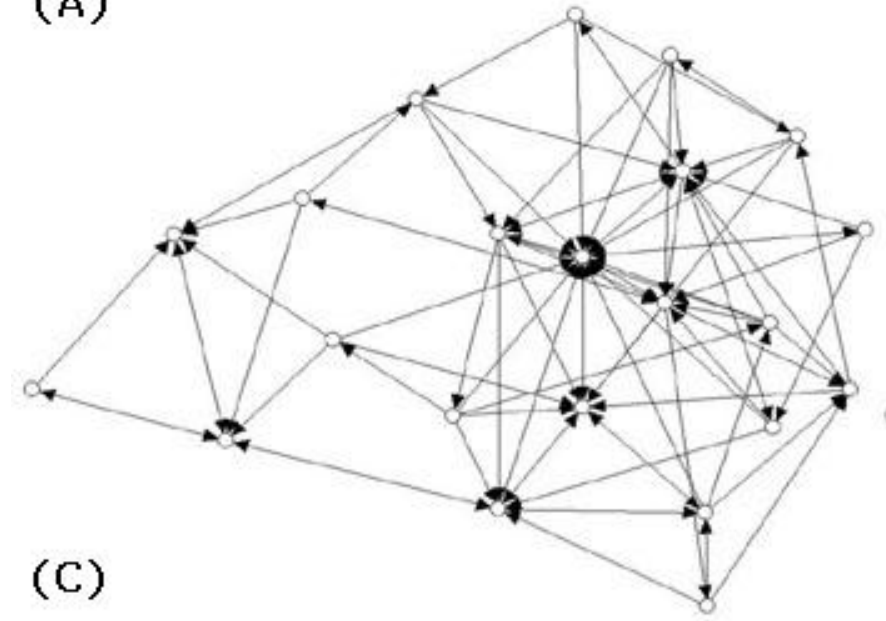

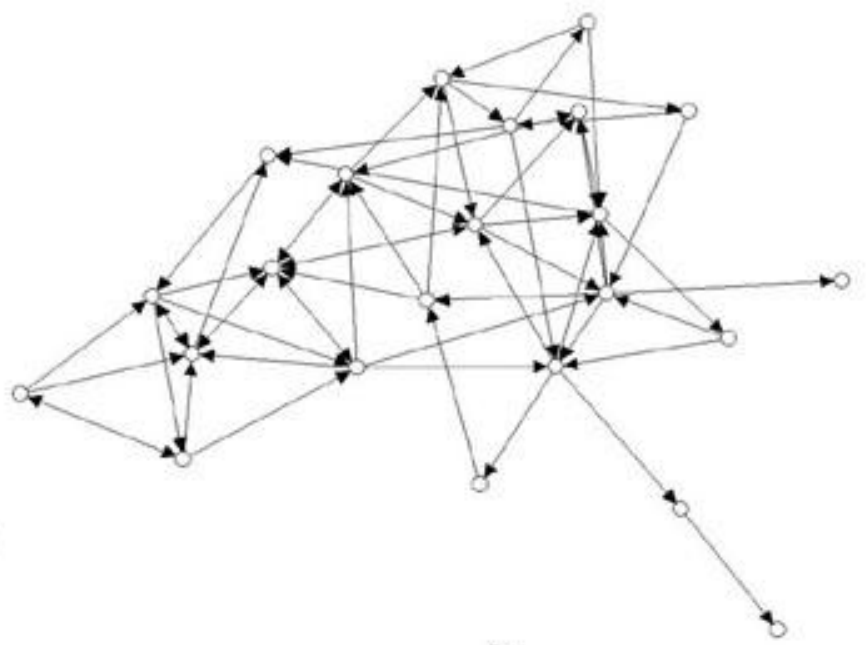

(B)

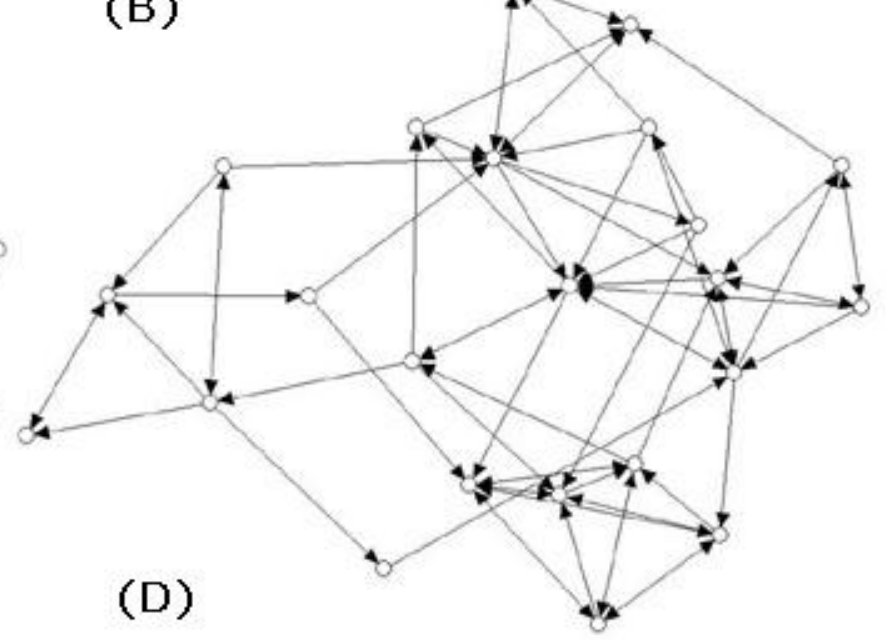

compared among the four networks(Freeman 1979, Degenne and Forsé 1999).

All analyses were performed using UCINET 6 and Netdraw software (Borgatti et al. 2002). Network densities and centrality parameters were analyzed using ANOVA for structural differences; the categorical variables were analyzed using twotailed t-tests. All statistical tests were performed using SAS version 8.0 (SAS 1999).

\section{RESULTS}

For ties averaged over the four networks, a significantly higher density of ties was present among a small group of farmers, i.e., the core, than between core and periphery, periphery and core, and periphery and periphery $(P<0.0017$; Table 2$)$. This suggests that core-periphery structure occurs within these farming communities. Structurally, there was little difference among the four communities because there was no significant difference in the 
density of ties within and between core and peripheral positions across all advice networks $(P$ $>0.05)$.

Within the predefined regional categories, no group was significantly represented in the core position $(P$ $=0.063$; Table 3); both settlers and local members were highly sought. Significantly more farmers in the core than in the periphery were involved in community activities $(P=0.035$; Table 3$)$. Both core and peripheral members participated in the observation of fellow farmers and subsequent adoption of practices $(P=0.728$; Table 3$)$, suggesting the occurrence of imitation processes.

Averaged over the four networks, $84 \%$ of core members sought some form of external formal information from outside the immediate community, from the radio, nongovernmental organizations, or government institutions such as the Ministry of Agriculture, thus functioning as possible bridging links (Table 4). In contrast, significantly fewer peripheral members, i.e., $32 \%$, actively sought information from formal sources $(P=0.0137$; Table $4)$. However, the information sought by core and peripheral members was similar, including, but not limited to, pest and disease control and recommended densities for cocoa plantations. As expected, all farmers relied on their local social networks for informal information such as on shade management, particularly species selection and site planting patterns (Table 4). Interestingly, the majority of core members, i.e., $92.5 \%$ averaged over the four networks, conducted farmer-initiated field trials and self-guided on-farm experimentation. The information sought from these informal trials was often related to the appropriate selection of species and densities (Table 4).

The three centrality parameters were used to compare the degree of similarity among the four community networks. There was no significant difference among network degree or betweenness parameters $(P>0.05$; Table 5). However, closeness was greater in Network 3 than in the other three networks (Table 5).

\section{DISCUSSION}

\section{Agroforestry advice networks}

Core farmers sought advice from other core members more often than from peripheral farmers, resulting in a high level of communication within a small group (Table 2). Low tie density was observed between the two structural positions. Overall, a relatively small, dense group of farmers was sought by the larger farming community for advice on farming practices. Previous studies suggest that core-periphery structures evolve from a purposeful selection of specific actors with an identifiable attribute that allows for entry into core membership (Barsky 1999). This phenomenon resulted in the observed emergent structure: a distinct group of farmers that received a high volume of queries from advice seekers.

\section{Advice seeking: characteristics of network structure}

Often, migrant farmers counter reductions in access to formal information by communicating amongst themselves (Romani 2003), thus producing new information and promoting knowledge ties within an isolated group. Although our results indicate that this process occurred to some extent, core membership was not strictly reserved for farmers that had kin ties, nor did settler farmers cluster amongst themselves (Table 3). By examining the core structure composition and observing links between settler and local farmers, we found that these two relational groups were not isolated and that they had connections through advice ties.

The slight over-representation of settler farmers in the core position is presumably a result of multiple factors. Researchers often assume that innovations are introduced by high-status group members (e.g., Rogers 1995); however, marginal individuals are more likely to introduce or adopt innovations because they receive less pressure for social conformity (Menzel 1960, Becker 1970). Thus, new ideas may be transferred by settler farmers who adapt their practices to the new environment. The introduction of new farmers who have lost their previous associations enhances the opportunity to activate new ties (Simmel 1922). Although kin structure can encourage information flow, 
Table 2. Density of farmer ties in each position-to-position interaction, i.e., core to core, core to periphery, periphery to core, and periphery to periphery, for four community networks and averaged over the four networks.

\begin{tabular}{lllc}
\hline \hline Community network & & \multicolumn{2}{l}{ Structural position } \\
\cline { 2 - 4 } & & Core & Periphery \\
\hline Network 1 & Core & 0.500 & 0.102 \\
& Periphery & 0.163 & 0.077 \\
Network 2 & Core & 0.500 & 0.088 \\
& Periphery & 0.098 & 0.099 \\
Network 3 & Core & 0.548 & 0.095 \\
& Periphery & 0.314 & 0.095 \\
Network 4 & Core & 0.850 & 0.022 \\
& Periphery & 0.056 & 0.154 \\
Networks $1-4 \dagger$ & Core & $0.60 \pm 0.169$ & $0.08 \pm 0.037$ \\
& Periphery & $0.16 \pm 0.113$ & $0.11 \pm 0.033$
\end{tabular}

$\dagger$ Mean \pm SE tie density for the four community networks combined.

homophily can also impede information transfer (Warriner and Moul 1992). Our data suggest that there were minimal effects of social proximity on the formation of the informal advice structure. Greater heterogeneity among core farmers may in fact lead to a higher likelihood of knowledge transfer.

Shared experience often increases the likelihood of tie formation, imitation, and the diffusion of practices (Valente 1995, Axelrod 1997, Romani 2003). This trend was evident because of the significant participation of core farmers in community activities (Table 3). However, it is difficult to determine whether core farmers were sought more frequently for advice because they were involved in community activities or whether core farmers were attracted to venues in which to learn and share knowledge and thus organized themselves around a similar focus (Feld 1981). It may well be a combination of these behaviors that results in highly participative farmers. Although increased collaboration may impede the durability of an idea or practice (Haggith et al. 2003), our results support previous research that indicates the positive effects of cooperative labor on the adoption of an idea or practice, specifically for small-scale farmers (Boahene et al. 1999), as well as tie formation (Feld 1981).

For the most part, we focused on the identification of verbal ties between farmers: To seek a person for advice implies some element of discussion. However, based on interview data, farmers occasionally indicated geographic proximity as a mode of knowledge acquisition via the observation of another farmer because information transfer also occurred through observation with minimal verbal 
Table 3. Percentages of core and periphery members who identified themselves as settler farmers (regional), who reported involvement in community activities (involvement), and who reported imitation of other farmers' practices (imitation) for the four community networks.

\begin{tabular}{|c|c|c|c|c|c|c|}
\hline \multirow{3}{*}{$\begin{array}{l}\text { Community ne- } \\
\text { twork }\end{array}$} & \multicolumn{6}{|c|}{ Surveyed attribute } \\
\hline & \multicolumn{2}{|c|}{ Regional } & \multicolumn{2}{|c|}{ Involvement } & \multicolumn{2}{|c|}{ Imitation } \\
\hline & Core & Periphery & Core & Periphery & Core & Periphery \\
\hline Network 1 & 43 & 43 & 72 & 50 & 72 & 50 \\
\hline Network 2 & 83 & 41 & 50 & 35 & 50 & 53 \\
\hline Network 3 & 86 & 53 & 100 & 47 & 72 & 27 \\
\hline Network 4 & 80 & 33 & 60 & 28 & 0 & 33 \\
\hline$P$ value $\dagger$ & \multicolumn{2}{|c|}{0.063} & \multicolumn{2}{|c|}{0.035} & \multicolumn{2}{|c|}{0.728} \\
\hline
\end{tabular}

$\dagger$ The percentages of farmers in the core and periphery were compared for each attribute over all four networks using $t$-tests.

exchange. In most instances, farmers revealed subsequent follow-up discussion with the observed farmer, resulting in a high probability of capturing these ties in the larger relational data set and analyzing them within the network analysis. There was no difference in the percentage of core or peripheral farmers who participated in imitation (Table 3 ) because many farmers readily observed another farm and subsequently adopted new practices such as pruning methods, planting density, and the management of organic matter and shade trees. The imitated farmers perhaps demonstrated clear signs of successful farming practices such that high productivity was achieved on these farms. Because local-level imitation may be central to the movement of information (Rogers 1995, Valente 1995, Axelrod 1997, Haggith et al. 2003), further reports on diffusion processes are necessary to understand the dynamic nature of technique assimilation.

\section{Consequences of network structure for agroforestry practices}

Core members of the advice networks sought some form of external formal information from outside the immediate community (Table 4), thus functioning as possible bridging links. The presence of these bridge ties between the community and outside institutions suggests a pathway for information infiltration. Presumably, these connections may counteract the frequently observed minimal movement of information to all community members (Boahene et al. 1999). Although peripheral farmers sought similar types of externally sourced information, they sought such information less often than did core farmers.

Both core and peripheral farmers sought information on farm pests and disease and answers to current farm problems predominately from outside the community. In contrast, information on 
Table 4. Percentages of farmers that sought information from various sources. The most highly mentioned types of information are listed.

\begin{tabular}{|c|c|c|c|c|c|c|}
\hline \multirow[t]{2}{*}{$\begin{array}{l}\text { Group memb- } \\
\text { ership }\end{array}$} & \multirow[t]{2}{*}{$\begin{array}{l}\text { Source of } \\
\text { information }\end{array}$} & \multicolumn{4}{|c|}{$\begin{array}{l}\text { Percentage of farmers that sought } \\
\text { information }\end{array}$} & \multirow[t]{2}{*}{ Type of information sought } \\
\hline & & $\mathrm{N} 1 \dagger$ & $\mathrm{N} 2$ & $\mathrm{~N} 3$ & N4 & \\
\hline \multirow[t]{3}{*}{ Core } & Formal & 60 & 86 & 100 & 90 & $\begin{array}{c}\text { Pest control, disease control, planting } \\
\text { density }\end{array}$ \\
\hline & Informal & 100 & 100 & 100 & 100 & $\begin{array}{l}\text { Species selection, farm establishment, } \\
\text { planting patterns, shade management, } \\
\text { organic matter management }\end{array}$ \\
\hline & $\begin{array}{l}\text { On-farm } \\
\text { experimentation }\end{array}$ & 100 & 80 & 100 & 90 & $\begin{array}{l}\text { Species selection, planting density, organic } \\
\text { matter management }\end{array}$ \\
\hline Periphery & Formal & 28 & 41 & 21 & 39 & $\begin{array}{c}\text { Pest control, disease control, planting } \\
\text { density }\end{array}$ \\
\hline
\end{tabular}

$†$ Community network (N) 1-4.

general farm management such as species selection, organic matter and shade tree management, and tree and crop densities tended to be sought within the community. These particular farm management techniques presumably relied on local ecological knowledge within the community, with on-farm experimentation as the main source of knowledge of agroforestry management. The majority of highly sought farmers conducted on-farm experimentation (Table 4). In these experiments, farmers investigated the differences in cocoa tree growth between sites or under different shade trees, or the planting of previously unused species on small plots of land, resulting in a source of original information on farming practices under local conditions. Regardless of whether the information came from outside or within the community, informal ties were used as a fundamental means to transfer original or pre-existing information from one farmer to another. Thus, there were multiple sources of information introduction for farmers, as well as a balance between formal and informal sources of information within the networks.
Seemingly, the majority of advice ties were motivated by farming practices because social proximity was not identified as a driving factor in forming the network structure. However, other types of tie-creating mechanisms are possible: Ties other than those associated with the sharing of knowledge may promote part of the network structure configuration. Interestingly, several peripheral farmers were sought by core farmers (Table 2). Individual social capital may influence particular advice seeking ties, with apparent consequences for network structure (Lin 2002). Theoretically, the strength of ties, particularly those associated with local leaders and/or client relations, may in fact drive some tie configurations (Granovetter 1973, Hansen 1999).

Advice network structure, however, may lead to an obvious imbalance of social capital within a community. Although benefits to management may be derived from increased community social capital (Grant 2001, Pretty 2003), enhanced individual social capital may indeed result in inequity within a farming community whereby certain farmers can 
Table 5. Mean (SD) of the degree, closeness, and betweenness parameters averaged over all farmers in each of four community networks.

\begin{tabular}{|c|c|c|c|c|}
\hline \multirow{3}{*}{ Community network } & \multicolumn{4}{|c|}{ Parameter } \\
\hline & \multirow[t]{2}{*}{ Degree } & \multicolumn{2}{|c|}{ Closeness } & \multirow[t]{2}{*}{ Betweenness } \\
\hline & & In & Out & \\
\hline Network 1 & $14.5(11.54)$ & $24.5(8.98)$ & $20.1(3.96)$ & $9.9(7.95)$ \\
\hline Network 2 & $12.1(6.91)$ & $18.5(1.73)$ & $31.5(11.36)$ & $7.7(5.83)$ \\
\hline Network 3 & $18.6(17.22)$ & $42.3(11.49)$ & $40.8(6.32)$ & $7.7(7.61)$ \\
\hline Network 4 & $14.0(8.47)$ & $34.0(9.88)$ & $26.3(2.84)$ & $9.0(9.43)$ \\
\hline
\end{tabular}

maintain their structural position by the control of information. It is possible that an individual's social capital may be reinforced over time as a function of his or her position in the network. For example, core farmers will increase their centrality over time because of the inequitable distribution of information; core farmers showed a greater tendency to seek and use external sources of information than did peripheral farmers. Conversely, it is possible that over time, the network structure may reduce the partitioning of farmers because relatively greater information is gained in the network as a whole, and community social capital is enhanced.

\section{Similarity among farmer networks}

Although there was some variation in the centrality parameters (Faust and Skvoretz 2002) among the networks, there was an apparent emerging pattern. The significantly higher closeness for Network 3 than for the other networks (Table 5) may be attributable to the generally denser arrangement of Network 3. In general, dissimilarity among the networks was low across all communities; highly comparable network structures were realized from each community of interviewed farmers. Further advancement of the multicommunity approach used here will provide greater rigor of network results. The replication among communities allowed whole network structures, not just characteristics of networks, to be compared statistically and revealed possible universal characteristics of advice seeking, particularly with regard to agroforestry techniques.

\section{CONCLUSIONS}

As is evident from the social network analysis, an identifiable and consistent network structure did indeed exist within these farming communities, and a simple core-periphery model was suitable to characterize this structure. Core membership was not limited to well-established, local farmers in the community; thus, ties within the core position were not necessarily between socially proximate farmers. This phenomenon suggests a lack of homophily among highly sought farmers, presumably leading to a high likelihood of information transfer (Warriner and Moul 1992). Highly sought farmers were more apt to be involved in community activities than were farmers who were not highly sought, promoting the likelihood of tie formation among core farmers. Both farmer-derived and formal sources of information flowed from farmer to farmer via network ties. Although farming practices may also diffuse via imitation, further 
research is required for a more detailed analysis of this process.

There are several implications for agroforestry management practices, specifically within farming communities with limited formal sources of information. The identification of highly sought farmers may play a critical role in the introduction, transfer, and implementation of new agroforestry techniques. The promotion of community involvement may facilitate the transfer of information, not simply to introduce information, but also to promote social exchange and interaction, strengthen pre-existing informal source networks, and increase social proximity among farmers. Specialized formal information is introduced into the network by highly sought farmers, possibly reinforcing the social capital of these individuals. However, original and accessible information is also produced by on-farm experimentation. Informal advice networks are instrumental in the successful transfer of this available information throughout the farming community and provide a foundation for community-based adaptive management.

Responses to this article can be read online at:

http://www.ecologyandsociety.org/vol12/iss2/art32/responses/

\section{Acknowledgments:}

We thank all participants in this study. We are grateful to the Faculty of Renewable Natural Resources, Kwame Nkrumah University of Science and Technology, Ghana, for research support. We acknowledge field assistance by J. Hagan and E. Dawoe and constructive comments by two anonymous reviewers. Financial support for this study was provided by the Natural Sciences and Engineering Research Council of Canada.

\section{LITERATURE CITED}

Amanor, K. S. 1994. The new frontier. Farmer responses to land degradation: a West African study. UNRISD, Geneva, Switzerland.

Axelrod, R. 1997. The complexity of cooperation: agent-based models of competition and collaboration. Princeton University Press, Princeton, New Jersey, USA.
Barsky, N. P. 1999. A core/periphery structure in a corporate budgeting process. Connections 22:1-29.

Becker, M. H. 1970. Sociometric location and innovativeness: reformulation and extension of the diffusion model. American Sociological Review 35:267-282.

Beer, J., R. Muschler, D. Kass, and E. Somarriba. 1997. Shade management in coffee and cacao plantations. Agroforestry Systems 38:139-164.

Boahene, K., T. A. B. Snijders, and H. Folmer. 1999. An integrated socioeconomic analysis of innovation adoption: the case of hybrid cocoa in Ghana. Journal of Policy Modeling 21(2):167-184.

Bodin, Ö., B. Crona, and H. Ernstson. 2006. Social networks in natural resource management: What is there to learn from a structural perspective? Ecology and Society 11(2): r2. [online] URL: http:/ /www.ecologyandsociety.org/vol11/iss2/resp2/.

Boni, S., R. I. Nuhu, F. Reuter, and G. Da Re. 2004. Anthropological, environmental and soils assessment of the Sefwi Wiawso District, Ghana. Ricerca e Cooperazione, Rome, Italy.

Borgatti, S. P., and M. G. Everett. 1999. Models of core/periphery structures. Social Networks 21:375-395.

Borgatti, S. P., M. G. Everett, and L. C. Freeman. 2002. UCINET 6 for Windows: software for social network analysis. Analytic Technologies, Lexington, Kentucky, USA. Available online at: http://www.a nalytictech.com/.

Burt, R. S. 1992. Structural holes: the social structure of competition. Harvard University Press, Cambridge, Massachusetts, USA.

Coleman, J. S. 1990. Foundations of social theory. Harvard University Press, Cambridge, Massachusetts, USA.

Conley, T., and C. Udry. 2001. Social learning through networks: the adoption of new agricultural technologies in Ghana. American Journal of Agricultural Economics 83:668-673.

Crona, B., and Ö. Bodin. 2006. What you know is who you know? Communication patterns among resource users as a prerequisite for co-management. Ecology and Society 11(2): 7. [online] URL: http:// 
www.ecologyandsociety.org/vol11/iss2/art7/.

Davidson-Hunt, I. J. 2006. Adaptive learning networks: developing resource management knowledge through social learning forums. Human Ecology 34:593-614.

Degenne, A., and M. Forsé. 1999. Introducing social networks. Sage Publications, Thousand Oaks, California, USA.

Faust, K., and J. Skvoretz. 2002. Comparing networks across space and time, size and species. Sociological Methodology 32:267-299.

Feld, S. L. 1981. The focused organization of social ties. American Journal of Sociology $\mathbf{8 6}$ (5):1015-1035.

Fortes, M. 1950. Kinship and marriage among the Ashanti. Pages 252-284 in A. R. Radcliffe-Brown and D. Forde, editors. African systems of kinship and marriage. Oxford University Press, London, UK.

Foster, A. D., and M. R. Rosenzweig. 1995. Learning by doing and learning from others: human capital and technical change in agriculture. Journal of Political Economy 103(6):1176-1209.

Freeman, L. C. 1979. Centrality in social networks: conceptual clarification. Social Networks 1:215-239.

Ghana Statistical Service. 2000. Population and housing census: summary report of final results. Ghana Statistical Service, Accra, Ghana.

Granovetter, M. 1973. The strength of weak ties. American Journal of Sociology 78:1360-1380.

Grant, E. 2001. Social capital and community strategies: neighbourhood development in Guatemala City. Development and Change 32:975-997.

Haggith, M., R. Prabhu, C. J. Pierce Colfer, B. Ritchie, A. Thomson, and H. Mudavanhu. 2003. Infectious ideas: modelling the diffusion of ideas across social networks. Small-Scale Forest Economics, Management and Policy 2(2):225-239.

Hanneman, R. A., and M. Riddle. 2005. Introduction to social network methods. University of California, Riverside, California, USA. [online textbook] URL: http://www.faculty.ucr.edu/ hanneman/ nettext/.
Hansen, M. T. 1999. The search-transfer problem: the role of weak ties in sharing knowledge across organization subunits. Administrative Science Quarterly 44(1):82-111.

Hartemink, A. E. 2005. Nutrient stocks, nutrient cycling, and soil changes in cocoa ecosystems: a review. Advances in Agronomy 86:227-253.

Isaac, M. E., V. R. Timmer, and S. J. QuashieSam. 2007. Shade tree effects in an 8-year-old cocoa agroforestry system: biomass and nutrient diagnosis of Theobroma cacao by vector analysis. Nutrient Cycling in Agroecosystems 78:155-165.

Kiptot, E., S. Franzel, P. Hebinck, and P. Richards. 2006. Sharing seed and knowledge: farmer to farmer dissemination of agroforestry technologies in western Kenya. Agroforestry Systems 68:167-179.

Lin, N. 2001. Social capital: a theory of social structure and action. Cambridge University Press, Cambridge, UK.

Lyon, F. 2000. Trust, networks and norms: the creation of social capital in agricultural economies in Ghana. World Development 28:663-681.

Marsden, P. V. 2005. Recent developments in network measurement. Pages 8-30 in P. J. Carrington, J. Scott, and S. Wasserman, editors. Models and methods in social network analysis. Cambridge University Press, Cambridge, UK.

McPherson, M., L. Smith-Lovin, and J. M. Cook. 2001. Birds of a feather: homophily in social networks. Annual Review of Sociology 27:415-444.

Menzel, H. 1960. Innovation, integration, and marginality: a survey of physicians. American Sociological Review 25:176-187.

Mortimore, M. J., and W. M. Adams. 2001. Farmer adaptation, change and 'crisis' in the Sahel. Global Environmental Change 11:49-57.

O'Neal Campbell, M. 2004. The role of socioenvironmental networking in the sustainability of rain-fed agriculture in the coastal savanna of Ghana. Geojournal 61:79-88.

Pretty, J. 2003. Social capital and the collective management of resources. Science 302: 1912-1914. 
Rogers, E. M. 1995. Diffusion of innovations. Fourth edition. Free Press, New York, New York, USA.

Romani, M. 2003. Love thy neighbor? Evidence from ethnic discrimination in information sharing within villages in Côte d'Ivoire. Journal of African Economies 12(4):533-563.

SAS. 1999. SAS software version 8. SAS Institute Inc., Cary, North Carolina, USA.

Simmel, G. 1922. Conflict and the web of associations. Free Press, Glencoe, Illinois, USA.

Valente, T. W. 1995. Network models on the diffusion of innovations. Hampton Press, Cresskill, New Jersey, USA.

Ward, W. E. F. 1958. A history of Ghana. Revised second edition. Allen \& Unwin, London, UK.

Wilks, I. 1993. Forests of gold: essays on the Akan and the Kingdom of Asante. Ohio University Press, Athens, Ohio, USA.

Warriner, G. K., and T. M. Moul. 1992. Kinship and personal communication network influences on the adoption of agriculture conservation technology. Journal of Rural Studies 8:279-291. 